\title{
PEMBINAAN PENYUSUNAN LAPORAN KEUANGAN DENGAN PENGGUNAAN SAK EMKM PADA PELAKU UMKM DI KAVLING FLAMBOYAN
}

\author{
Viola Syukrina E Janrosl ${ }^{1 \text { )* }}$, Kiki Futich Rosida ${ }^{2)}$, Annisa Anugrah Maulidina ${ }^{3)}$ \\ Program Studi Akuntansi, Fakultas Ekonomi, Universitas Putera Batam, Indonesia ${ }^{1), 2), 3)}$ \\ Pos-el: viola.myudzz21@gmail.com \\ *Corresponding author
}

\begin{abstract}
Abstrak
Pengelolaan keuangan menjadi salah satu aspek penting bagi kemajuan suatu usaha.Pengelolaan keuangan dapat diedukasi melalui akuntansi. Akuntansi merupakan proses sistematis untuk menghasilkan informasi keuangan yang dapat digunakan untuk pengambilan keputusan bagi penggunanya. Penggunaan akuntansi dapat mendukung kemajuan UMKM khususnya dalam hal keuangan.Fenomenanya dalam menjalankan aktivitas usaha seringkali pengelola UMKM merasa kesulitan dalam melakukan pencatatan terhadap apa yang terjadi pada operasional usahanya. Fenomena ini menarik minat tim pengusul pengabdian untuk mengadakan kegiatan pengabdian yang bersifat pembinaan kepada 3 pelaku UMKM yang ada di Kavling Flamboyan. Ada pelaku usaha pisang krispy, bakso bakar dan kue bawang. Pengabdian Masyarakat ini dilaksanakan Agar pelaku usaha bisa membuat pembukuan yang terstruktur dalam laporan keuangan yang baik sesuai standar EMKM dan mampu mengidentifikasi kebutuhan penambahan modal kerja melalui penyisihan pendapatan atau pengajuan kredit bank, untuk itu pengabdian ini memberikan pembinaan bagaimana cara membuat laporan keuangan berdasarkan SAK EMKMMetode yang diterapkan dalam pembinaan ini dengan menggunakan metode ceramah, tutorial dan diskusi. Hasil dari kegiatan pengabdian ini dapat menambah wawasan dan berbagi ilmu pengetahuan kepada masyarakat yang ada, khususnya pelaku usaha pisang krispy, bakso bakar dan kue bawang yang ada di Kavling Flamboyan
\end{abstract}

Kata kunci: SAK EMKM, Laporan Keuangan

\section{Abstract}

Financial management is one of the important aspects for the progress of a business. Financial management can be educated through accounting. Accounting is a systematic process to produce financial information that can be used for decision making for its users. The use of accounting can support the progress of MSMEs, especially in financial matters. Phenomenon in carrying out business activities often MSME managers have difficulty in recording what happened in the operations of their business. This phenomenon attracted the interest of the service proponent team to conduct coaching service activities to 3 MSMEs in the Flamboyan Plot. There are krispy banana businessmen, grilled meatballs and onion cakes. Community Service is carried out so that business people can make structured bookkeeping in good financial statements according to EMKM standards and are able to identify the need for additional working capital through income provision or bank credit applications, for this service provides guidance on how to make financial statements based on EMKM SAK Method applied in this coaching using lecture methods, tutorials and discussions. The results of this service activity can add insight and share knowledge to the community, especially the krispy banana businessmen, grilled meatballs and onion cakes that are in the Flamboyan Plot

Keywords: SAK EMKM, Financial Statements 


\section{PENDAHULUAN}

Perkembangan jumlah Usaha Mikro Kecil Menengah (UMKM) dari tahun ke tahun semakin bertambah. Bisa dilihat dari jumlah UMKM Kecamatan Sagulung ditahun 2014 ada 34 pelaku usaha, tahun 2015 bertambah 12 pelaku usaha dan tahun 2016 bertambah 1 pelaku usaha yang menjadi binaan UMKM Kota Batam(Neli \& Tertarik, 2017). Saat ini UMKM Kota Batam membentuk tim pendamping MEA (Masyarakat Ekonomi Asean) yang merupakan pegawai kontrak kementrian koperasi yang bertugas memberikan edukasi mengenai standar produksi produk dan pengarahan mengenai legalitas usaha. Target dari masing-masing tim MEA ini adalah pelaku usaha bisa mandiri, bisa melakukan kegiatan import dan ekspor. (Tertarik, 2017).

Pengelolaan keuangan menjadi salah satu aspek penting bagi kemajuan suatu usaha.Pengelolaan keuangan dapat diedukasi melalui akuntansi. Akuntansi merupakan proses sistematis untuk menghasilkan informasi keuangan yang dapat digunakan untuk pengambilan keputusan bagi penggunanya. Penggunaan akuntansi dapat mendukung kemajuan UMKM khususnya dalam hal keuangan.

Peningkatan laba juga dapat direncanakan dengan menggunakan akuntansi. Dengan tingkat laba yang semakin meningkat, perkembangan UMKM akan menjadi lebih baik sehingga UMKM akan benar-benar menjadi salah satu solusi bagi masalah perekonomian di Indonesia. Segala bentuk upaya pemecahan masalah atas berbagai kendala yang dihadapi UMKM dalam peningkatan kinerjanya.Hal ini disebabkan banyak UMKM lebih berfokus pada kegiatan operasional sehingga pencatatan dan pelaporan seringkali terabaikan.Tanpa catatan dan laporan yang baik evaluasi kinerja UMKM tidak mudah untuk dilakukan.

Dalam menjalankan aktivitas usaha seringkali pengelola UMKM merasa kesulitan dalam melakukan pencatatan terhadap apa yang terjadi pada operasional usahanya (Shonhadji, A, \& Djuwito, 2017). Kesulitan itu menyangkut aktivitas dan penilaian atas hasil yang dicapai oleh setiap usaha.Apalagi kalau harus dilakukan pengukuran dan penilaian atas aktivitas yang terjadi dalam kegiatan usaha ataupun non usaha.Seringkali dalam skala usaha kecil menengah hasil usaha dikatakan bagus jika pendapatan sekarang lebih tinggi daripada pendapatan sebelumnya.Padahal indikator keberhasilan tidak hanya diukur dari pendapatan saja, diperlukan pengukuran dan pengelompokan transaksi atau kegiatan yang terjadi serta pengikhtisaran transaksi-transaksi tersebut.(Setyorini, Ari Istiningrum, Adhi Nugroho, \& Murti Sagoro, 2012).

Pelaku UMKM merasa kesulitan jika harus menggunakan akuntansi dalam kegiatan bisnisnya.Hal ini dikarenakan tidak adanya pedoman atau buku yang dapat dijadikan referensi untuk belajar mengelola keuangan UMKM.Buku-buku yang beredar saat ini memang belum ada yang fokus pada pengelolaan keuangan UMKM. Terdapat beberapa judul buku akuntansi untuk UMKM, namun melihat isinya sama seperti buku akuntansi untuk perusahaan besar. Banyak transaksi yang terjadi di UMKM seperti barter atau tukar jasa namun tidak diberikan contoh dalam buku sehingga ketika transaksi tersebut terjadi, pelaku UMKM lebih memilih untuk tidak mencatatnya. Apabila terdapat banyak transaksi serupa dan tidak dicatat tentunya akan membawa dampak negatif bagi kinerja keuangan suatu usaha. Selain belum ada buku yang 
secara spesifik membahas transaksi dalam UMKM, banyak pelaku UMKM yang enggan membaca buku.

Berdasarkan permasalahan tersebut, perlu diadakan kegiatan pembinaan bagi pelaku UMKM dalam hal mengelola keuangan dengan menggunakan akuntansi.Program pembinaan penyusunan laporan keuangan dengan penggunaan SAK EMKM pada pelaku UMKM di Kavling Flamboyan.Adanya pembinaan ini diharapkan pelaku UMKM dapat mengetahui perkembangan usaha dan dapat memanfaatkan akuntansi guna mendukung kemajuan UMKM.

Berdasarkan analisis situasi dapat dirinci permasalahan yang ada, adapun masalah-masalah yang ditemukan adalah:

1. Pelaku usaha belum memiliki pembukuan yang terstruktur dalam laporan keuangan yang baik sesuai standar EMKM.

2. Mitra belum mampu mengidentifikasi kebutuhan penambahan modal kerja melalui penyisihan pendapatan atau pengajuan kredit bank.

Berdasarkan permasalahan yang telah diuraikan program pengabdian masyarakat kali ini akanmemberikan materi gambaran umum dan mensosialisasikan tentang laporan keuangan berdasarkan SAK EMKM dan memberikan materi akuntansi mulai dari pencatatan sampai dengan membuatlaporan keuangan berdasarkan SAK EMKM. Agar pelaku usaha bisa membuat pembukuan yang terstruktur dalam laporan keuangan yang baik sesuai standar EMKM dan mampu mengidentifikasi kebutuhan penambahan modal kerja melalui penyisihan pendapatan atau pengajuan kredit bank, untuk itu pengabdian ini memberikan pembinaan bagaimana caramembuatlaporan keuangan berdasarkan SAK EMKM.

\section{METODE}

Pengabdian masyarakat ini direncanakan pada pertengahan bulan Juli dengan target sasaran adalah 3 pelaku UMKM yang ada di Kavling Flamboyan.Ada pelaku usaha pisang krispy, bakso bakar dan kue bawang.

Berdasarkan identifikasi masalah di atas, agar memperoleh manfaat dari pengabdian ini, maka metode yangditawarkan dalam pengabdian ini adalah sebagai berikut:

1. Metode ceramah, dimana dosen memberikan materi gambaran umum dan mensosialisasikan tentang laporan keuangan berdasarkan SAK EMKM.

2. Metode praktek, dimana para mahasiswa secara bergantian menyampaikan materi akuntansi mulai dari pencatatan sampai dengan membuat laporan keuangan berdasarkan SAK EMKM dan memberikan contoh kasus dari materi yang disampaikan.

3. Metode diskusi, peserta pembinaan diberikan kesempatan untuk mendiskusikan permasalahan yang berkaitan dengan laporan keuangan berdasarkan SAK EMKM dan membahas contoh kasus secara bersama-sama. 
Dalam kegiatan pengabdian "Pembinaan" ini membutuhkan beberapa peralatan seperti:

1. Papan tulis

2. Spidol dan Penghapus

3. Infocus

4. Buku/ Modul Laporan Keuangan

5. Alat Tulis

6. Laptop

7. Kalkulator

Keberlanjutan kegiatan diharapkan akan berlanjut untuk pembinaan selanjutnya dengan kosep yang lama namun dengan tema yang baru yaitu memaksimalkan laba usaha dengan pelaporan keuangan yang tepat dan akurat. Tema baru ini merupakan tema lanjutan dari laporan keuangan berdasarkan SAK EMKM pada pelaku umkm. Karena setelah pelaku usaha mampu membuat laporan keuangan berdasarkan SAK EMKM, akan dilanjutkan dengan pembuatan laporan keuangan dengan memaksimalkan profit.

\section{HASIL DAN PEMBAHASAN}

Berdasarkan pembinaan yang telah dilakukan pada 3 pelaku UMKM yaitu pelaku usaha pisang krispy, bakso bakar dan kue bawang yang ada di Kavling Flamboyan, diharapakan dapat memberikan dampak yang positif kepada para peserta, kepada dosen dan mahasiswa yang melakukan pembinaan, secara lebih rinci hasil yang dicapai dari pelaksanaan pembinaan tersebut dapat diuraikan antara lain sebagai berikut:

1. Terjalinnya kerjasama antara Universistas Putera Batam dengan masyarakat luar.

2. Menambah wawasan dosen dan mahasiswa dalam hal pemahaman tentang penyusunan pembukuan yang terstruktur dalam laporan keuangan yang baik sesuai standar EMKM.

3. Menambah wawasan peserta pembinaan yaitu pelaku usaha pisang krispy, bakso bakar dan kue bawang yang ada di Kavling Flamboyan.

4. Mengembangkan dan berbagi ilmu pengetahuan kepada masyarakat yang ada, khususnya pelaku usaha pisang krispy, bakso bakar dan kue bawang yang ada di Kavling Flamboyan. 


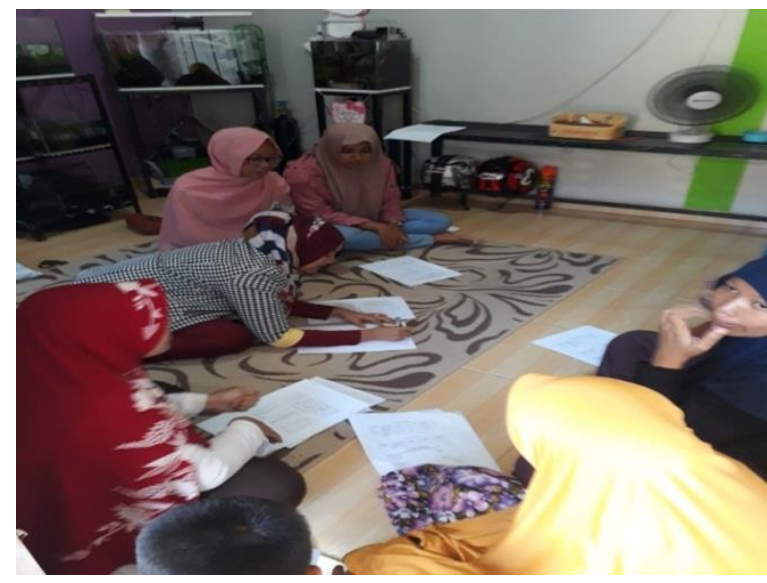

\section{Gambar 1: Saat menjelaskan materi SAK EMKM}

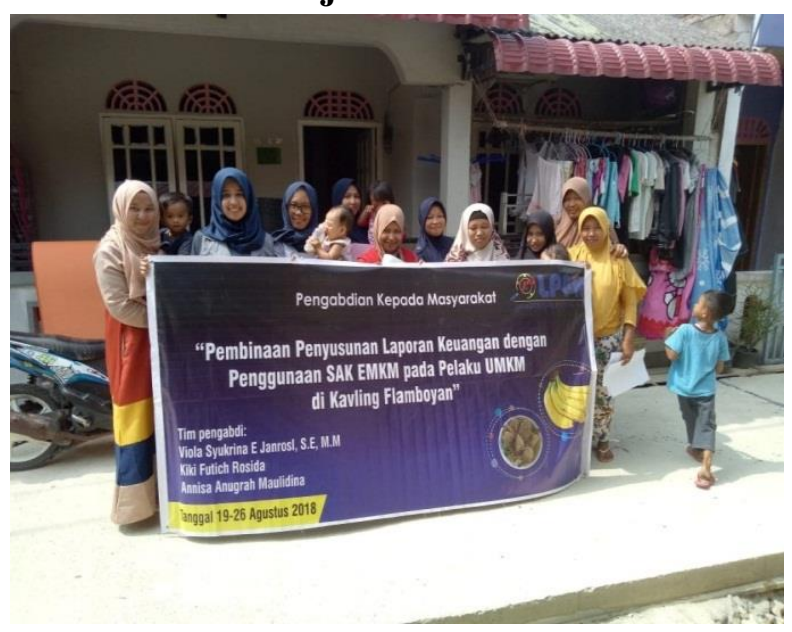

Gambar 2: Foto bersama diakhir acara pengabdian

Berikut ini adalah hasil laporan keuangan berdasarkan SAK EMKM dari usaha KRE PISANG CRISPY sebagai berikut:

Tabel 1

KRE PISANG CRISPY

NERACA

TAHUN YANG BERAKHIR 31 JULI 2018

\begin{tabular}{|c|l|c|c|l|c|}
\hline No & \multicolumn{1}{|c|}{ Akun } & Jumlah & No & \multicolumn{1}{|c|}{ Akun } & Jumlah \\
\hline 101 & $\begin{array}{l}\text { Aset Lancar } \\
\text { Kas }\end{array}$ & 7.000 .000 & 201 & $\begin{array}{l}\text { Kewajiban Jangka } \\
\text { Pendek } \\
\text { Hutang Usaha }\end{array}$ & 4.400 .000 \\
102 & $\begin{array}{l}\text { Piutang Usaha } \\
103\end{array}$ & 800.000 & 202 & Putang Gaji & 1.000 .000 \\
\end{tabular}




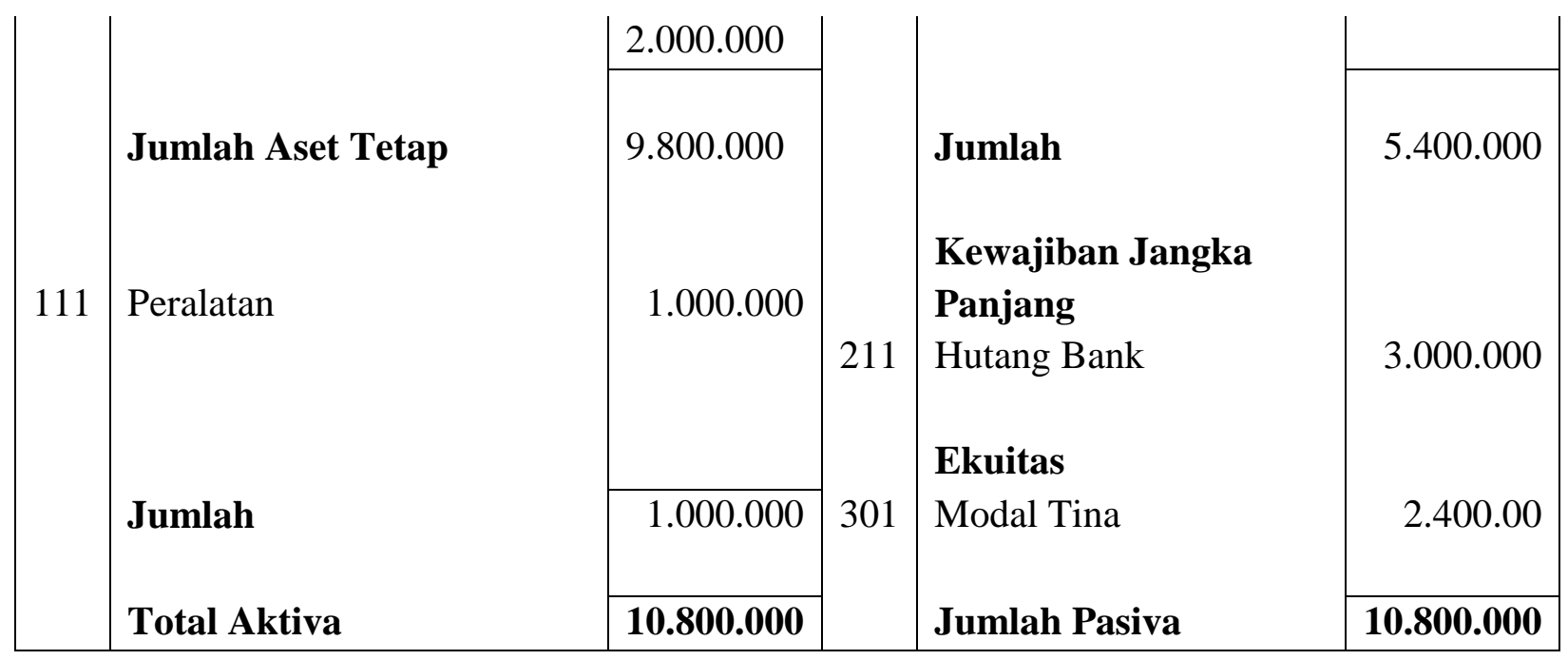

Tabel 2

KRE PISANG CRISPY

LAPORAN LABA RUGI

TAHUN YANG BERAKHIR 31 JULI 2018

Pendapatan :

Pendapatan usaha

Rp $\quad 5.000 .000$

Harga Pokok Penjualan

$(1.000 .000)$

BEBAN :

Biaya gaji karyawan

Biaya operasional

700.000
$\quad 300.000$

Biaya listrik dan air

350.000

\section{LABA BERSIH}

( Rp1.350.000)

Rp 3.650.000

Pelaksanaan kegiatan pembinaan penyusunan Laporan Keuangan berdasarkan SAK EMKM berjalan dengan lancar dan peserta dapat mengikutinya dengan baik. Beberapa peserta yang memiliki latar belakang pendidikan akuntansi cukup mudah mengikui materi yang disampaikan, namun sebagian besar lagi belum mengerti mengenai fungsi Laporan Keuangan berdasarkan SAK EMKM, bahkan beberapa ada yang menganggap bahwa menyusun Laporan Keuangan berdasarkan SAK EMKMmerepotkan, dan menghabiskan waktu.

Secara umum kegiatan pembinaaan ini berlangsung dengan lancar.Hal tersebut dapat dicapai berkat dukungan dan bantuan dari ibu Yenni pemilik usaha pisang crispy.Namun 
pembinaan ini juga tidak lepas dari faktor-faktor yang menghambat jalannya kegiatan tersebut.Karena faktor tersebut bukan menjadi penghalang utama karena dosen dan mahasiswa sebagai panitia penyelenggara kegiatan berusaha mengatasi permasalahan-permasalahan tersebut.Itu terbukti dari telah berlangsungnya kegiatan hingga berakhir dengan lancar.Berikut dijabarkan lebih rinci faktor penghambat dan pendukung jalannya kegiatan pembinaan.

Faktor pendukung kegiatan pembinaan penyusunan Laporan Keuangan berdasarkan SAK EMKM adalah:

1. Pelaku usaha antusias mengikuti pembinaan yang dilihat dari respon para peserta dalam berdiskusi dan bertanya, bahkan berkeinginan agar kegiatan serupa tetap berlanjut di masa yang akan datang.

2. Fasilitas tempat pembinaan yang mendukung kegiatan pembinaan sehigga materi pembinaan penyusunan Laporan Keuangan berdasarkan SAK EMKM tersebut dapat disaksikan peserta dengan lebih jelas.

Adapun hambatan yang dialami pada saat melaksanakan kegiatan pembinaan penyusunan Laporan Keuangan berdasarkan SAK EMKM tersebut antara lain:

1. Keikut sertaan atau kehadiran peserta sesuai dengan undangan. Namun saat acara pengabdian berlangsung lampu mati. Acara kami lanjutkan di teras rumah warga.

2. Penghambat lainnya adalah bersifat teknis seperti papan tulis, infocus dan LCD.

\section{SIMPULAN}

Kegiatan pembinaan penyusunan Laporan Keuangan berdasarkan SAK EMKM kepada pisang krispy, bakso bakar dan kue bawang yang ada di Kavling Flamboyan berjalan dengan lancar. Pelaku usaha cukup antusias mengikuti kegiatan hingga acara selesai dan merasakan manfaat pelatihan bagi kemajuan usaha mereka. Beberapa peserta juga sudah mulai memahami pentingnya penyusunan Laporan Keuangan berdasarkan SAK EMKM dan memahami bagai mana cara penyusunan Laporan Keuangan berdasarkan SAK EMKM yang baik dan benar.

\section{DAFTAR PUSTAKA}

Neli, \& Tertarik, J. (2017). Perkembangan UMKM Kecamatan Sagulung. Batam.

Setyorini, D., Ari Istiningrum, A., Adhi Nugroho, M., \& Murti Sagoro, E. (2012). Pelatihan Akuntansi UMKM Bagi Usaha Mikro Kecil Menengah (UMKM) Untuk Meningkatkan Kinerja Keuangan Perusahaan, (April), 1-18.

Shonhadji, N., A, L. A., \& Djuwito. (2017). Penerapan Penyusunan Laporan Keuangan Pada Usaha Kecil Menengah Berdasarkan SAK EMKM di Surabaya, 130-136.

Tertarik, J. (2017). Pembentukan Tim Mea (Masyarakat Ekonomi Asean). Batam. 